\section{O passado, o presente, o futuro \\ e uma nova categoria social: o servidor público aposentado}

CARVALHO, Abdias Vilar de. Antes do futuro, o destino: trajetórias de vida do servidor público aposentado. Recife: UFPE, 2014.

Paulo Renan Rodrigues de França*

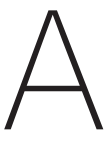
presente obra do sociólogo Abdias Vilar de Carvalho é fruto de sua tese de doutorado, defendida em 2002, na Universidade Estadual de Campinas (Unicamp). O livro trata de fatos recentes da história brasileira, mais especificamente da história do funcionalismo público no período entre 1990 e 2001, tendo como pano de fundo os mandatos presidenciais de Fernando Collor de Melo e Fernando Henrique Cardoso.

A análise do autor concentra-se nos processos de aposentadoria em massa, que ocorreram no período supracitado, tratando dos motivos que levaram os servidores públicos à aposentadoria, as implicações decorrentes e como os aposentados encararam esta situação em relação às suas famílias, aos seus colegas de trabalho e à sociedade em geral. Na literatura política sobre o Brasil recente, o movimento dos servidores públicos aposentados por causa da disponibilidade não mereceu o mínimo registro; nesta obra ela é fartamente explorada.

O livro conta com nove capítulos, mas pode muito bem ser dividido, ainda que assim não o seja, em quatro partes distintas, porém complementares. A primeira parte serve como introdução para a análise do autor; nela, Abdias traça um panorama da situação em que o país vivia em relação aos governos Collor e FHC. Durante o período de 1991 a 1998, a sociedade brasileira presenciou um intenso processo de aposentadoria

de servidores públicos, sem precedentes, (1) por conta de seu alcance numérico; (2) pela forma como os servidores foram conduzidos à aposentadoria; e (3) como essa nova categoria social se inseriu socioculturalmente no país.

Para analisar o processo de aposentadoria em massa dos servidores, Carvalho recorre aos estudos do historiador alemão Reinhart Koselleck, que nos brinda com as categorias analíticas: "espaços de experiência" e "horizontes de expectativas".
Recebido: 11.03 .15

Aprovado: 03.06.16
* Mestre em desenvolvimento sustentável pelo Centro de Desenvolvimento Sustentável da Universidade de Brasília (CDS-UnB). $<$ p_renan10@ hotmail.com> 
Segundo Koselleck (2006), experiência e expectativa entrelaçam passado e futuro. Encontramos isso nos relatos em Carvalho, pois o autor afirma que é preciso "fazer e refazer", "compreender e apreender", "citar e explicar" o passado: "como experiência e não como algo que já morreu" (p. 30), mas como algo que faz toda a diferença no presente de cada sujeito. Logo, expectativa é o projeto idealizado, que foi realizado ou não, que, junto à experiência (as marcas da idade, amadurecimento pessoal e profissional), formam uma base do passado, "testemunho, referência e legitimidade do presente; e projeção do futuro" (p. 30).

O autor recorre à noção de tempo sempre presente, concepção agostiniana, onde lembrança/memória, visão e esperança constituem-se no arco temporal de uma vida. Em Gurvitch, Carvalho lança mão das noções de "tempo histórico" e "tempo sociológico". Outros autores, além do já citado Koselleck, como Braudel, Hobsbawn e Le Goff, trazem sua contribuição ao entender a história como uma totalidade dos tempos. Mas é com Paul Ricœur que Carvalho mais dialoga teoricamente, ao trazer a ideia de que é "fundamental compreender o tempo presente pela junção das outras temporalidades", logo a memória e o esquecimento exercem papéis fundamentais para a análise do livro.

Dois acontecimentos são essenciais para o nosso entendimento, a saber, a Lei $\mathrm{n} . \stackrel{\circ}{ }$ 8.112, de 11 de dezembro de 1990, que regulamentou os artigos constitucionais referentes aos direitos do funcionalismo público, unificando os variados regimes de contração, estendendo aos funcionários celetistas os mesmos direitos e vantagens concedidas aos estatutários. E o segundo acontecimento, refere-se às Emendas Constitucionais n.․19, de 4 de junho de 1998, e n. 20, de 15 de dezembro de 1998 . Quanto a esta última - que diz respeito à estabilidade -, ela alterava o regime de aposentadoria vigente, especialmente no que concerne à contagem de tempo para a garantia de direitos.

A hipótese que o autor traz para justificar a onda de aposentadorias nos governos Collor e FHC está calcada em dois fatores distintos. No governo Collor, a questão da disponibilidade gerou forte desconfiança por parte dos servidores. Este fator foi fartamente analisado no livro. Por outro lado, o governo FHC, apoiado na proposta de reforma do Estado, juntamente com a reforma da Previdência, o clima de insegurança em relação aos direitos adquiridos impulsionou uma nova leva de aposentadorias.

Em resumo, quando o trabalho foi realizado para a elaboração da tese, a conjuntura do país apresentava o seguinte quadro:

1. havia insegurança pessoal, gerada pelas propostas governamentais de reforma da previdência; 
2. um clima desfavorável ao servidor público visto pela opinião pública como alguém privilegiado, com altos salários e pouco trabalho, houve uma espécie de campanha governamental contra a imagem do servidor; e

3. o arrocho salário.

Talvez, o grande mérito do livro é o fato de trazer a visão do servidor público aposentado. O autor afirma que as análises sociológicas que enfocam este período da história nacional estão associadas, em sua maioria, ao papel do Estado e nos custos econômicos da Previdência Social. É neste ponto que a primeira parte do livro serve de ponte para a segunda. Após tratar das razões que levaram mais de 200 mil servidores públicos à aposentadoria, antes mesmo do tempo previsto, o autor passa a apresentar estes servidores. A segunda parte do livro trata do processo de "desconsagração" do servidor perante a opinião pública.

Esta parte é muito interessante, pois aborda um assunto que muitas vezes é encarado com jocosidade. Tornou-se popular vincular a imagem do servidor público a alguém que ganha muito bem, tem vários privilégios, mas que é improdutivo, não faz o seu trabalho como se deve, em resumo: que trabalha pouco. Nas entrevistas realizadas pelo autor, junto aos aposentados do serviço público, constatou-se que isso causa constrangimento aos mesmos, pois ninguém deseja estar associado a esta imagem negativa.

Esta visão foi endossada pelo próprio governo, que em uma campanha para demonstrar a desnecessidade de várias instituições públicas, com vistas à redução do Estado, passou a uma espécie de caça às bruxas, como relatam algumas entrevistas. Especialmente no governo de Fernando Collor de Melo, isto apareceu de forma intensificada, ainda mais pelo slogan de campanha que identificava o então presidente como o "caçador de marajás". Esses marajás seriam os servidores públicos e seus altos salários.

É neste momento que o tema da disponibilidade entra em cena. Esta "caça aos marajás" preparou o caminho para a extinção, privatização de empresas públicas, demissão e disponibilidade dos servidores federais, pois estava comprovada a ineficiência de várias instituições e a necessidade premente de modernização do Estado, enxugamento da máquina estatal. Dentre outras coisas, isto desencadeou efeitos não contabilizados nas contas públicas, mas na vida e na saúde de muitos servidores.

A incerteza dos funcionários sobre o seu futuro dentro das instituições, acabou por paralisá-los. Alguns adoeceram e tornaram-se aos poucos "improdutivos", quem sabe dando mais razão para os críticos do serviço público. Outros entraram em de- 
pressão, outros morreram de desgosto. Isto está plenamente documentado nas entrevistas realizadas. As falas emocionadas fazem do texto algo muito mais humano, algo que vai além das meras descrições sociológicas. A derradeira hora da demissão foi um fantasma para vários servidores, que se viam como sobre uma corda bamba, a hora da demissão fazia-se sempre presente.

A disponibilidade gerou problemas entre colegas de trabalho, pois quais seriam os critérios que colocariam alguém nas listas de disponibilidade e demissão? Isto não era claro. Alguns relatam que havia colegas que mereciam estar na lista de demissão (seja por incompetência para o trabalho, ou displicência para com as suas funções etc), mas nunca o foram; ao contrário de alguns que notadamente tinham suas habilidades reconhecidas. Conflitos internos cresceram dentro das instituições, gerando um clima quase insuportável para a realização das atividades cotidianas.

A terceira parte traz o porquê do nome do livro (Antes do futuro, o destino: trajetórias de vida do servidor público aposentado). O servidor público, como todo trabalhador, esperava cumprir seu tempo de trabalho e aposentar-se de uma forma planejada. Entretanto, com os problemas causados pelo processo de disponibilidade, a insegurança e reforma da Previdência, muitos optaram pela aposentadoria antecipada, com medo de perder benefícios. O autor compara futuro e destino no seguinte aspecto: o futuro é algo planejado, construído no presente, imaginado e desejado, ou seja, sob controle. O destino é algo incerto, que foge às rédeas de nossas experiências e expectativas.

A antecipação da aposentadoria por motivos que fogem às expectativas "normais", lançou no destino os servidores públicos aposentados, não foi algo devidamente planejado e desejado, pelo contrário, foi feito por necessidade e causou dores físicas e emocionais. A terceira parte do livro é dedica a esta contradição entre o futuro planejado e a incerteza causada pelo destino. A aposentadoria, que antes era vista como prêmio, tornou-se um tipo de punição, que gerou mudanças abruptas no rumo de vida a seguir por cada aposentado.

A interrupção da vida de trabalho não era pra ser um ato arbitrário, e sim algo desejado. Sobre este aspecto, o autor identifica que a aposentadoria, como reação às ameaças, deve ser examinada como estratégia de sobrevivência, de garantia de benefícios. A confiança entre governo e servidor não teria o mesmo grau e status, a partir deste processo iniciado no governo Collor e expandido no governo FHC. Até hoje o episódio interfere nas candidaturas sob a sigla do PSDB.

Há outro aspecto importante nesta obra: a dupla relação entre o, agora, aposentado e o funcionário público (ou ex-funcionário). O recém-aposentado é: 
1. ainda funcionário, "sua cultura e estratégia de vida situam-se num universo definido pela posição funcional, onde ele se comporta marcadamente como um ainda funcionário", o cordão umbilical ainda não foi cortado.

2. é alguém que tem um enfrentamento diário com sua vida "ex-serviço". "No segundo tipo de relação, aposentado [...] reclama do achatamento salarial, das ameaças aos direitos garantidos, como, por exemplo, o pagamento da contribuição previdenciária e do desligamento do aposentado dos benefícios concedidos ao ativo". O aposentado é um ser do passado e do presente.

Por fim, chegamos à quarta e última parte do livro. Aqui, o autor inicia os capítulos finais com uma reflexão teórica sobre o que é ser aposentado e o que é aposentadoria, sobre o tempo livre, e sobre esta nova categoria social, que é o aposentado do serviço público, categoria inserida em outra categoria social, os idosos. Na verdade, a relação aposentado/idoso é uma das formas de definir o campo do aposentado. No contexto dos aposentados do serviço público, alvos desta obra, os mesmos rejeitam o rótulo de idoso. Não há esquema para enquadrar o aposentado nesse ou naquele modelo (alguns aposentados mal têm 50 anos).

Nesta última parte vemos como os aposentados, em sua maioria, não se consideram como tais. A noção de aposentadoria reveste-se de vários sentidos, muitas vezes associados à inatividade, enquanto os entrevistados não se viam como pessoas inativas, mas como pessoas que após concluírem um ciclo de suas vidas, estavam iniciando outro, em que poderiam dedicar-se aos projetos inacabados de outrora, mas acima de tudo poderiam dedicar-se mais à família.

- Não faça isso. Começar uma história com "naquele tempo" envelhece a gente. Não faça isso. ("Seu" Afonso para D. Isaura, em Chuvas de verão, filme de Cacá Diegues, que retrata a vida de um recém aposentado e o redescobrimento da vida após os 60).

Podemos identificar, ao longo do texto, os sentidos atribuídos pelos entrevistados, no que tange à aposentadoria, quais sejam:

1. aposentadoria como direito e expectativa;

2. aposentadoria como projeto de sociedade;

3. aposentadoria como processo cheio de conflitos;

4. aposentadoria como ato individual, desejado, perseguido; 
5. aposentadoria como projeto não acabado;

6. aposentadoria como "estar parado".

O trabalho de identificar a análise de cada um desses pontos e a descoberta de tantos outros, deixo aos leitores.

Nos momentos finais do livro, a análise do autor recai sobre o aposentado como um todo, demonstrando a diversidade de manifestações do ser aposentado. A idade não é mais característica fundamental, mas o conjunto de como o sujeito se enxerga e sente. Nesta quarta parte, podemos afirmar que o autor deixa de lado as relações dos aposentados do funcionalismo público com suas respectivas (ex) instituições, e tenta refletir sobre a relação idoso-aposentado, é neste ponto que a narrativa perde um pouco o foco e a força, mas nada que venha a prejudicar o todo. Poderia ser colocado em anexo.

Antes do futuro, o destino é um livro importante para quem quiser compreender um pouco mais sobre um momento de nossa história recente, a saber a onda de aposentadorias que assolou o funcionalismo público, lançando mão de uma análise bastante qualitativa, tomando como base os relatos dos atores que mais foram impactados em todo o processo e como foi sua transição entre o funcionalismo público e a vida pós-trabalho.

\section{Referências}

KOSELLECK, Reinhart. Futuro passado: contribuição à semântica dos tempos históricos. Rio de Janeiro: Contraponto/Editora PUCRio, 2006.

GURVITCH, Georges. La vocation actuelle de la sociologie. Paris: PUF , 1969.

BRAUDEL, Fernand. Escritos sobre a história. São Paulo: Perspectiva, 1992.

—. La historia y las ciencias sociales. Madrid: Alianza Editorial, 1989.

LE GOFF, Jacques. História e memória. 3. ed. Campinas: Editora Unicamp, 1994.

HOBSBAWM, Eric. Sobre história. São Paulo: Companhia das Letras, 1998.

—. Era dos Extremos: o breve século XX: 1914-1991. São Paulo: Companhia das Letras, 1995.

RICCEUR, Paul. Le temps et les philosophies. Paris: Payot; Unesco, 1976.

A memória, a história, o esquecimento. Campinas: Editora Unicamp, 2007. 